\title{
Fate and seasonal variation of endocrine-disrupting chemicals in a sewage treatment plant with $\mathrm{A} / \mathrm{A} / \mathrm{O}$ process
}

\author{
Yafeng $\mathrm{Nie}^{\mathrm{a}, \mathrm{b}}$, Zhimin Qiang ${ }^{\mathrm{a}, *}$, Heqing Zhang ${ }^{\mathrm{a}}$, Weiwei Ben ${ }^{\mathrm{a}}$ \\ a State Key Laboratory of Environmental Aquatic Chemistry, Research Center for Eco-Environmental Sciences, Chinese Academy of Sciences, 18 Shuang-qing Road, \\ Beijing 100085, China \\ ${ }^{\mathrm{b}}$ Institute of Chemical Defense, Beijing 102205, China
}

\section{A R T I C L E I N F O}

\section{Article history:}

Available online 1 February 2011

\section{Keywords:}

Endocrine-disrupting chemicals

Fate

Seasonal variation

Sewage treatment plant

$\mathrm{A} / \mathrm{A} / \mathrm{O}$ process

\begin{abstract}
A B S T R A C T
The fate and seasonal variation of several typical endocrine-disrupting chemicals (EDCs), including estrone (E1), 17 $\beta$-estradiol (E2), 17 $\alpha$-ethinylestradiol (EE2), estriol (E3), bisphenol A (BPA) and 4-nonylphenol (NP), were investigated in a municipal sewage treatment plant (STP) employing an anaerobic/ anoxic/oxic (A/A/O) process located in Beijing, China by monitoring their concentrations in both wastewater and activated sludge in four seasons throughout 2009. Results indicate that in summer, the examined STP could effectively remove $75.4 \%$ of E1 and more than $90 \%$ of all other studied EDCs from the wastewater. The biodegradation in the $\mathrm{A} / \mathrm{A} / \mathrm{O}$ process was the primary removal mechanism. Moreover, the removal of EDCs from the wastewater in the A/A/O bioreactor and their concentrations in the solid phase of return sludge exhibited an obvious seasonal fluctuation. The concentrations of EDCs in the effluent and return sludge were much higher in winter and spring than in summer and autumn, which was closely related to the microbial activity and the concentration of mixed liquor suspended solids (MLSS). Therefore, this study may raise a particular concern regarding the removal of EDCs from wastewater and the disposal of excess sludge in cold seasons.
\end{abstract}

(C) 2011 Elsevier B.V. All rights reserved.

\section{Introduction}

In recent years, the negative effect of endocrine-disrupting chemicals (EDCs) present in the aquatic environment on wildlife and humans has been seriously concerned around the world [13]. EDCs are thought to be responsible for the decrease in both quality and quantity of human sperms and some serious diseases [4]. In the case of wildlife, even trace concentrations (at ng/L level) of $17 \beta$-estradiol (E2) or $17 \alpha$-ethinylestradiol (EE2) could induce the vitellogenin in male fish [5]. EDCs have been detected in various surface waters and sediments in China [6,7].

Previous studies have clearly shown that the municipal sewage treatment plants (STPs) are an important pollution source of EDCs released into the environment $[8,9]$. The natural/synthetic steroid estrogens and endocrine-disrupting phenolic compounds are two major classes of EDCs that have attracted the most attention of environmental researchers. The estrogens of natural origin include E2 and its main metabolites (i.e., estrone (E1) and estriol (E3)), which are largely present in human urine. EE2 is commonly used as a major ingredient in many oral contraceptives. These steroid estrogens have a high estrogenic effect. Bisphenol A (BPA) and 4-

\footnotetext{
* Corresponding author. Tel.: +86 10 62849632; fax: +86 1062843541 .

E-mail address: qiangz@rcees.ac.cn (Z. Qiang).
}

nonylphenol (NP) are industrial and household chemicals which have a less estrogenic capacity but are commonly detected at a much higher concentration than steroid estrogens in the STPs.

Continued research efforts have been made to investigate the occurrence, fate and behavior of these EDCs in the STPs [10-12]. Liu et al. [13] reported that the concentrations of estrogens were commonly detected at ng/L level, while those of phenolic compounds could reach $\mu \mathrm{g} / \mathrm{L}$ level in the STP effluent. Jin et al. [14] detected the concentrations of several estrogens and their estrogenicities in the influent and effluent of an STP with conventional primary and secondary treatments located in Wuhan, China. Zhou et al. [15] investigated the change of concentrations of eight EDCs in wastewater along the treatment processes of three STPs in Beijing. However, these studies only focused on the wastewater side, while the activated sludge side was largely overlooked. The reason probably lies in that the serious matrix interference makes it difficult to accurately quantify the amount of EDCs present in the activated sludge. However, Auriol et al. [16] pointed out that though the biodegradation by and/or the adsorption to activated sludge were generally presumed to be the main mechanism accounting for the removal of EDCs in the STPs, more information about EDCs in the activated sludge was required. Therefore, the concentrations of EDCs in both wastewater and activated sludge should be simultaneously determined to comprehensively understand their fate and behavior in the STPs. In addition, considering 


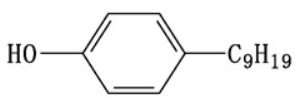

4-Nonylphenol (NP)<smiles>CC12CCC3c4ccc(O)cc4CCC3C1CCC2O</smiles>

17ß-Estradiol (E2)<smiles>CC(C)(c1ccc(O)cc1)c1ccc(O)cc1</smiles>

Bisphenol A (BPA)<smiles>C#CC1(O)CCC2C3CCc4cc(O)ccc4C3CCC21C</smiles>

$17 \alpha$-Ethinylestradiol (EE2)<smiles>CC12CCC3c4ccc(O)cc4CCC3C1CCC2=O</smiles>

Estrone (E1)

Fig. 1. Chemical structures of target EDCs.

that the microbial activity significantly relies on the wastewater temperature which varies significantly throughout one year in Northern China (e.g. Beijing), the seasonal variation of EDCs concentrations in the wastewater and activated sludge is also worthy of investigation.

Consequently, this work was to investigate the fate and seasonal variation of several typical EDCs, including E1, E2, EE2, E3, BPA and NP (Fig. 1), in both wastewater and activated sludge along different treatment processes of an STP located in Beijing throughout one year. The examined STP adopted an anaerobic/anoxic/oxic $(\mathrm{A} / \mathrm{A} / \mathrm{O})$ process as the core treatment unit. The results of this study are expected to improve the understanding of the fate and behavior of EDCs in the STPs.

\section{Experimental}

\subsection{Chemicals}

E1 (99\%) was purchased from Acros (NJ, USA), and E2 (97.0\%), E3 (99.0\%), BPA (99.9\%) and NP (a mixture of nine technical isomers with different branched side-chains) from Tokyo Chemical Industry (Tokyo, Japan). EE2 (98\%) and the internal standards (ISs), BPA- $d_{16}(98 \%)$ and E2- $d_{2}(98 \%)$, were purchased from Sigma-Al- drich (St. Louis, USA). Methanol (HPLC grade) was purchased from Fisher Chemicals (Pittsburg, USA); dichloromethane (ultra resianalyzed) from J.T. Baker (Deventer, The Netherlands); and hexane (HPLC grade) from J\&K Chemical (Beijing, China). $\mathrm{N}$, O-bis(trimethylsilyl)trifluoroacetamide (BSTFA) with $1 \%$ trimethylchlorosilan (TMCS), used as the derivatization reagent, was supplied by Fluka (Buchs, Switzerland). Silica gel and neutral aluminum oxide, both of 100-200 mesh and chromatography grade, were purchased from Sinopharm Chemical Reagent Co. (Beijing, China). Other chemicals were obtained from Beijing Chemical Reagents Company (Beijing, China) with at least analytical grade. Ultrapure water was produced by a Milli-Q-Plus system (Millipore, USA).

\subsection{Sewage treatment plant}

The process flow of the examined STP is illustrated in Fig. 2. The original sewage, composed of municipal and industrial wastewaters, first passed through the mechanical screen and aerated grit chamber. Then, the sewage was directed to the $\mathrm{A} / \mathrm{A} / \mathrm{O}$ bioreactor to remove the general organic substances and nutrients $(\mathrm{N}, \mathrm{P})$. The hydraulic retention time (HRT) of the bioreactor was about $14 \mathrm{~h}$, and the subsequent secondary sedimentation tank had an HRT of $6 \mathrm{~h}$. The secondary effluent was directly discharged to a

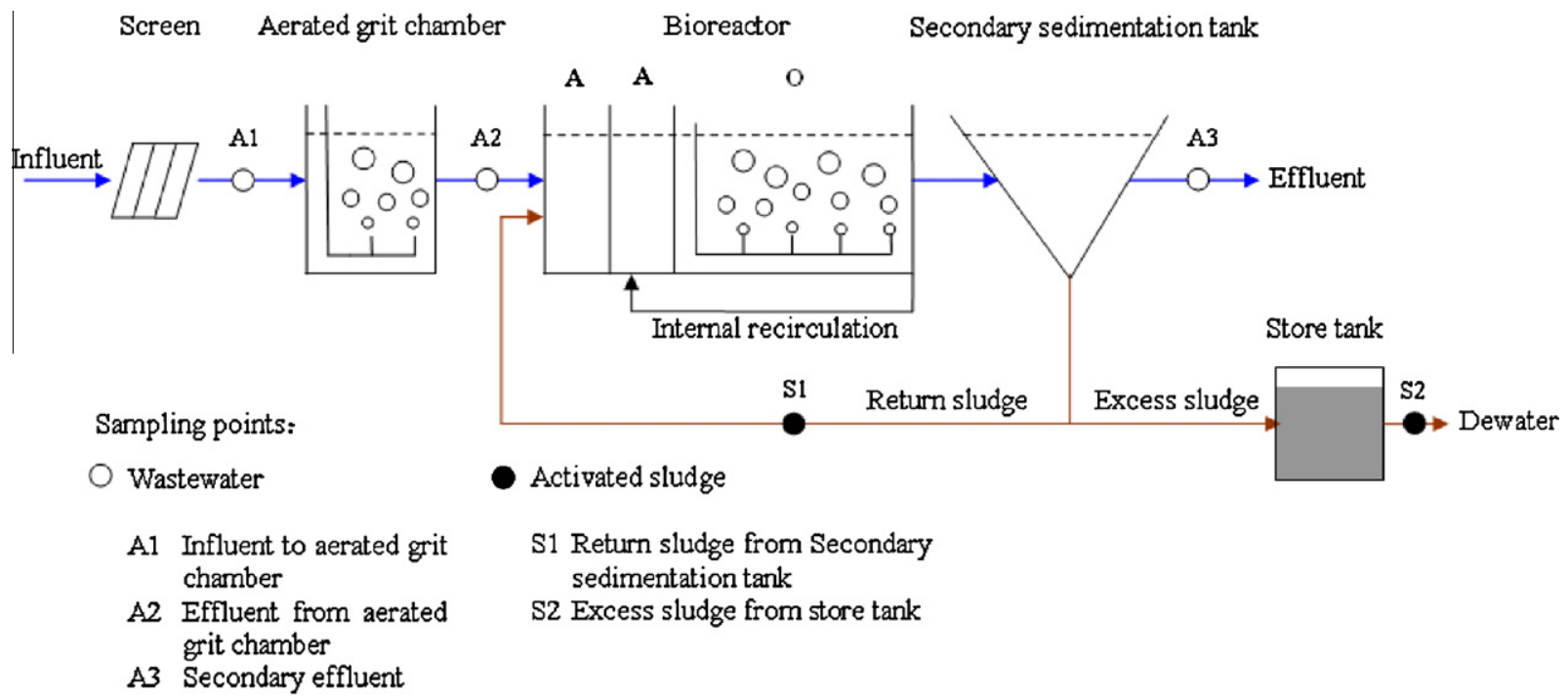

Fig. 2. Sampling points along the process flow of the studied STP. 
nearby river, while a part of the settled sludge was returned to the bioreactor and the remaining part was pumped into a storage tank as excess sludge. After being dewatered, the excess sludge was carried away for final disposal. The treatment capability of this STP was ca. 2,00,000 $\mathrm{m}^{3} /$ day. The $\mathrm{A} / \mathrm{A} / \mathrm{O}$ bioreactor was operated with a solid residence time (SRT) of 10-15 days, a typical range for a nitrification/denitrification process.

\subsection{Sample collection and pretreatment}

Sampling along different treatment processes in the STP was carried out in the summer of 2009. Fig. 2 shows the sampling sites with three points (A1-A3) for wastewater samples and two points (S1 and S2) for sludge samples. At each sampling site, three samples were separately taken for later extraction and gas chromatography-mass spectrometry (GC-MS) analysis. To investigate the seasonal variation of EDCs concentrations in the bioreactor and return sludge, additional sampling was conducted at A2 and S1 in other three seasons. After collection, all samples were stored in amber glass bottles into which $1 \%$ formaldehyde $(\mathrm{v} / \mathrm{v})$ was preadded to restrain the microbial activity and then taken back to the laboratory for analysis. The sampling time was set between 2:00 and 4:00 p.m. because the hourly fluctuation of the effluent estrogenicity was found to be insignificant on one sampling day except the morning period when a urine peak load usually appeared in the STP [17]. The samples were collected in four seasons on January 5 (winter), April 14 (spring), July 30 (summer) and November 3 (autumn) throughout 2009, corresponding to a wastewater temperature of $12,19,27$ and $18{ }^{\circ} \mathrm{C}$, and a mixed liquor suspended solids (MLSS) concentration in the return sludge of 5.11, $6.70,7.80$ and $10.31 \mathrm{~g} / \mathrm{L}$, respectively.

In laboratory, the wastewater samples were acidified to $\mathrm{pH} 2.5-$ 3.0 with $40 \% \mathrm{H}_{2} \mathrm{SO}_{4}(\mathrm{v} / \mathrm{v})$ and stored at $4{ }^{\circ} \mathrm{C}$ in refrigerator for analysis within $24 \mathrm{~h}$. The sludge samples were first centrifuged at $6000 \times \mathrm{g}$ for $20 \mathrm{~min}$ (Beckmann, J2-HS, USA) and divided into the liquid (i.e., interstitial wastewater in sludge) and solid phases. Afterwards, the liquid phase was pretreated in the same way as the bulk wastewater sample, while the solid phase was freeze-dried, stored at $-18{ }^{\circ} \mathrm{C}$ in refrigerator, and analyzed within one week.

\subsection{Sample analysis}

The target EDCs in the samples, including E1, E2, EE2, E3, BPA and NP, were simultaneously determined according to our previously developed method [18]. In brief, for the wastewater samples and the liquid phase of activated sludge samples, $40 \mathrm{ng}$ of BPA- $\mathrm{d}_{16}$ (for phenolic compounds) and $80 \mathrm{ng}$ of E2- $\mathrm{d}_{2}$ (for steroid estrogens) were spiked into $400 \mathrm{~mL}$ of sample as the ISs. After the sample was filtered through $1-\mu \mathrm{m}$ glass fiber filters, an Oasis HLB cartridge $(500 \mathrm{mg} / 6 \mathrm{~mL}$, Waters) and a Sep-Pak silica cartridge (500 mg/6 mL, Waters) were employed for solid-phase extraction (SPE) of the filtrate and cleanup of the matrix, respectively. The EDCs retained in the SPE cartridge were eluted with $10 \mathrm{~mL}$ of dichloromethane/acetone $(7: 3, v / v)$, and then the eluate was dried under a gentle stream of $\mathrm{N}_{2}$.

The freeze-dried solid phase of sludge sample $(1.0 \mathrm{~g})$ was first treated with ultrasonic liquid extraction (ULE) for three times. Each ULE used $5 \mathrm{~mL}$ of methanol/acetone $(1: 1, \mathrm{v} / \mathrm{v})$ under continuous ultrasonication for $10 \mathrm{~min}$. Three supernatants were collected after centrifugation and combined together. Thereafter, the ISs (i.e., $40 \mathrm{ng}$ of BPA- $\mathrm{d}_{16}$ and $80 \mathrm{ng}$ of $\mathrm{E} 2-\mathrm{d}_{2}$ ) were spiked inside. The extract from ULE was diluted with $300 \mathrm{~mL}$ of ultrapure water, and SPE was applied to further extract the target EDCs. Because the solid phase of sludge samples had a more complex matrix than the wastewater samples, a laboratory-made glass column packed with sodium sulfate, neutral aluminum oxide, silica gel and glass wool at different layers from top to bottom, was used to clean up the matrix. The final eluate was evaporated to about $1 \mathrm{~mL}$ in a rotary evaporator (Yarong, RE52AA, China) and further dried with a gentle stream of $\mathrm{N}_{2}$.

The above refined extracts from the wastewater and sludge samples were derivatized by BSTFA containing 1\% TMCS under the conditions of $70^{\circ} \mathrm{C}$ and ultrasonication, and eventually analyzed by GC-MS (7890A GC and 5975C MS, Agilent, USA). The operation conditions of GC-MS, quantification/confirmation ions of target EDCs, and the quantification method were detailed in our previous work [18].

The MLSS concentration was measured according to the Standard Methods [19]. The wastewater quality parameters, including chemical oxygen demand (COD), total nitrogen (TN) and total phosphorus (TP), were determined with Hach test kits using a UV-VIS spectrophotometer (Hach DR5000, USA).

\section{Results and discussion}

\subsection{Change of EDCs concentrations along different treatment processes in summer}

The concentrations of target EDCs in the wastewater and sludge samples collected from different treatment processes in the STP as

Table 1

Concentrations of studied EDCs in wastewater and sludge along different sewage treatment processes in summer (mean (SD), $n=3$ ).

\begin{tabular}{|c|c|c|c|c|c|c|c|c|c|c|}
\hline \multirow[t]{2}{*}{ Sampling points } & \multirow[t]{2}{*}{ Concentration symbol } & \multicolumn{6}{|c|}{ EDCs (ng/L) } & \multicolumn{3}{|c|}{ Wastewater characteristics (mg/L) } \\
\hline & & E1 & E2 & EE2 & E3 & BPA & NP & COD & $\mathrm{TN}$ & $\mathrm{TP}$ \\
\hline \multirow[t]{2}{*}{ A1 } & $C_{1}$ & 51.7 & 7.7 & 77.7 & 459.1 & 836.9 & 4941.5 & 203 & 58 & 2.7 \\
\hline & & $(0.9)$ & $(1.2)$ & $(2.2)$ & $(18.4)$ & $(87.2)$ & $(712.0)$ & (3) & (3) & $(0.2)$ \\
\hline \multirow[t]{2}{*}{ A2 } & $C_{2}$ & 51.6 & 6.9 & 75.7 & 387.2 & 994.5 & 6355.3 & 211 & 59 & 2.5 \\
\hline & & $(4.6)$ & $(0.7)$ & $(7.1)$ & $(10.8)$ & $(14.1)$ & $(192.7)$ & $(3)$ & $(2)$ & $(0.1)$ \\
\hline \multirow[t]{2}{*}{ A3 } & $C_{3}$ & 12.7 & ND & ND & ND & 3.7 & 429.5 & 18 & 17 & $<0.5$ \\
\hline & & $(0.3)$ & & & & $(0.2)$ & $(16.3)$ & $(1)$ & (1) & \\
\hline \multirow[t]{4}{*}{ S1 } & Liquid phase $L_{1}$ & 1.9 & ND & ND & ND & 7.6 & 441.3 & & & \\
\hline & & $(0.2)$ & & & & $(1.3)$ & $(39.7)$ & & & \\
\hline & Solid phase $X_{1}$ (ng/g SS) & 4.0 & ND & ND & ND & 18.9 & 3649.0 & & & \\
\hline & & $(0.9)$ & & & & $(5.4)$ & $(115.4)$ & & & \\
\hline \multirow[t]{2}{*}{$\mathrm{S} 2$} & Solid phase $X_{2}$ (ng/g SS) & 3.0 & ND & ND & ND & 20.1 & 3161.0 & & & \\
\hline & & $(0.5)$ & & & & $(3.2)$ & $(127.3)$ & & & \\
\hline \multicolumn{2}{|c|}{ Removal efficiency ${ }^{\mathrm{a}}(\%)$} & 75.4 & $>90.0^{\mathrm{b}}$ & $>95.0^{\mathrm{b}}$ & $>99.5^{\mathrm{b}}$ & 99.6 & 93.2 & 94.6 & 70.7 & 81.5 \\
\hline
\end{tabular}

ND, not detected.

a Removal efficiency $=\left(C_{1}-C_{3}\right) / C_{1} \times 100$

b The limits of quantification (LOQs) were taken as $C_{3}$ (E2: $0.8 \mathrm{ng} / \mathrm{L} ; \mathrm{EE} 2: 4.0 \mathrm{ng} / \mathrm{L} ; \mathrm{E} 3: 2.3 \mathrm{ng} / \mathrm{L} ;$ Ref. [18]). 
well as the wastewater characteristics are shown in Table 1 . In general, a large portion of the estrogenic materials excreted by humans are originally present in the conjugated forms (i.e., glucuronides and sulfates) which have a less estrogenic activity than their unconjugated (or free) forms. However, they may get deconjugated by microorganisms and thus converted into free estrogens during transport in the sewers. D'Ascenzo et al. [20] reported that the daily amounts of conjugated E1, E2 and E3 excreted by women were approximately 32,14 and $106 \mu \mathrm{g}$, respectively; so the mass ratio of conjugated E2 is about $9.2 \%$ in the three natural estrogens. However, the results $\left(C_{1}\right)$ in Table 1 show that the specific concentration ratio of E2, if only the three natural estrogens are considered, in the influent of aerated grit chamber was just $1.5 \%$ and obviously lower than that in the urine. It is inferred that the deconjugated E2 could be partially metabolized to E1 and E3 [21] in the sewers due to its high biodegradability [22], thus leading to an increase in the specific concentration ratios of E1 and E3 in $C_{1}$.

The comparison between $C_{2}$ and $C_{1}$ indicates that the concentrations of the phenolic compounds (i.e., BPA and NP) notably rose after the wastewater passed through the aerated grit chamber. It is likely that some organic compounds (including BPA and NP) originally adhering to the grits were peeled off due to the agitation of air. However, the concentrations of estrogens (except E3) remained quite stable after this process. It is known that the estrogens are more biodegradable than the phenolic compounds $[23,24]$, thus the amount of estrogens biodegraded might offset that desorbed from the grits in the aerated grit chamber. E3 is the least hydrophobic among all target estrogens since the $\log K_{o w}$ values of E1, E2, EE2 and E3 are 3.43, 3.94, 4.15 and 2.81, respectively [25]. Furthermore, E3 is more biodegradable than E1 and EE2 [26]. The two reasons tended to account for a notable (about $16 \%)$ removal of E3 in the aerated grit chamber. Andersen et al. [10] reported that the concentrations of estrogens did not significantly decrease in the primary effluent. Neither the aerated grit chamber nor the primary sedimentation tank could notably remove any target EDCs.

The wastewater characteristics in $C_{3}$ clearly show a high removal of COD, TN and TP, indicating a good performance of the $\mathrm{A} / \mathrm{A} / \mathrm{O}$ bioreactor in summer. In correspondence, an effective removal of target EDCs from the wastewater was also observed. Based on $C_{1}$ and $C_{3}$, the removal efficiency of each EDC in the wastewater was calculated and summarized in Table 1. Results indicate that among the steroid estrogens, E1 showed the lowest removal (75.4\%), whereas E2, EE2 and E3 were not detected in the secondary effluent. Baronti et al. [8] investigated the removal of steroid estrogens in six STPs located in Rome. They reported that the removal efficiencies of E1, E2, EE2 and E3 were 61\%, 85\%, 87\% and $95 \%$, respectively. It is generally considered that E1 sulfates cannot be effectively deconjugated in the sewers due to the lack of arylsulfatase enzyme. However, the deconjugation of E1 sulfates can readily take place in the STP, thus significantly increasing the concentration of free E1 in the effluent. In addition, E2 can be metabolized to E1 in the activated sludge process [27]. The two reasons seem to account for the least removal of E1 in the A/A/O process.

The concentration of NP reached its peak value $(6355.3 \mathrm{ng} / \mathrm{L})$ after the aerated grit chamber. Because NP is quite resistant to biodegradation [26], it retained a relatively high concentration level $(429.5 \mathrm{ng} / \mathrm{L})$ in the secondary effluent. Ying et al. [28] reviewed the NP concentrations in the STP effluents in eight countries and found a remarkable fluctuation which varied from less than the limit of detection (LOD) to $343 \mu \mathrm{g} / \mathrm{L}$. In comparison, the examined STP exhibited a favorable degradation of NP with a removal efficiency of $93.2 \%$ in the wastewater. With respect to BPA, though its influent concentration was the second highest $(836.9 \mu \mathrm{g} / \mathrm{L}), \mathrm{a}$ nearly complete removal (99.6\%) was achieved in the A/A/O pro- cess. Liu et al. [13] also reported that BPA was generally removed by more than $90 \%$ in the STPs. However, it should be pointed out that the removal efficiencies of target EDCs listed in Table 1 only represent the summer condition when the microorganisms are most active. Moreover, the conjugated forms of estrogens in the influent were not considered, which would otherwise increase the removal efficiencies of studied estrogens.

Since activated sludge commonly acts as a sink for hydrophobic EDCs, this study also analyzed the concentrations of target EDCs in both liquid and solid phases of return sludge collected from the secondary sedimentation tank (i.e., $X_{1}$ and $L_{1}$ ). The excess sludge in the storage tank was directly dewatered without digestion, and the liquid phase produced from the dewatering process was returned to the $\mathrm{A} / \mathrm{A} / \mathrm{O}$ bioreactor. Therefore, only the concentrations of EDCs in the solid phase were determined for the excess sludge. Results show that the solid phases of both return sludge $\left(X_{1}\right)$ and excess sludge $\left(X_{2}\right)$ had similar concentrations of EDCs, implying that the biodegradation of EDCs was insignificant in the storage tank.

\subsection{Fate of EDCS in the STP in summer}

There are three pathways for the removal/transport of EDCs in the STP: (1) biodegradation; (2) discharge into the aquatic environment with the secondary effluent; and (3) discharge with the excess sludge. Based on the mass balance of target EDCs and some important operational conditions including the flux of wastewater $\left(2,00,000 \mathrm{~m}^{3} /\right.$ day $)$ and the discharge rate of excess sludge $(1850 \mathrm{~kg}$ $\mathrm{SS} / \mathrm{h}$ ) in the STP, the mass flux ratios of studied EDCs through biodegradation, secondary effluent and excess sludge could be estimated, as shown in Table 2. Results indicate that biodegradation was the most important pathway for EDCs removal, which agrees with that reported by Pothitou and Voutsa [29]. Among all target EDCs, E1 showed the lowest mass flux ratio via biodegradation (74.2\%) but the highest mass flux ratio via the secondary effluent (24.6\%). NP exhibited the maximal mass flux ratio via the excess sludge $(9.9 \%)$ due to its highest hydrophobicity $\left(\log K_{o w}=4.48\right)$, and a relatively high mass flux ratio via the second effluent (6.8\%).

Andersen et al. [30] measured the solid-water distribution coefficients $\left(K_{d}\right)$ of several steroid estrogens between water and activated sludge particles and pointed out that the mass flux ratio of estrogens discharged with the excess sludge was below $1.8 \%$ if equilibrium conditions could be met in the STP.

\subsection{Seasonal variation of EDCs concentrations}

\subsubsection{Variation of EDCs concentrations in the influent and effluent of} the bioreactor

The concentrations of target EDCs in the influent of the $\mathrm{A} / \mathrm{A} / \mathrm{O}$ bioreactor and in both liquid and solid phases of the return sludge from the secondary sedimentation tank were analyzed in four seasons throughout 2009. The concentrations of EDCs in the liquid phase of return sludge were considered as same as those in the sec-

Table 2

Mass flux ratios of EDCs through three different pathways in summer (\%).

\begin{tabular}{lrlllrl}
\hline Pathways & E1 & E2 & EE2 & \multicolumn{1}{l}{ E3 } & BPA & \multicolumn{1}{l}{ NP } \\
\hline Biodegradation & 74.2 & $>86.5^{\mathrm{a}}$ & $>92.3^{\mathrm{a}}$ & $>99.2^{\mathrm{a}}$ & 99.2 & 83.3 \\
Secondary effluent & 24.6 & - & - & - & 0.4 & 6.8 \\
Excess sludge & 1.2 & - & - & - & 0.4 & 9.9
\end{tabular}

a E2, EE2 and E3 were not detected in the secondary effluent and excess sludge. To estimate the mass flux ratios of these compounds via biodegradation, their LOQs in the liquid and solid phases of activated sludge were taken as their ultimate concentrations in the secondary effluent and excess sludge, respectively. 


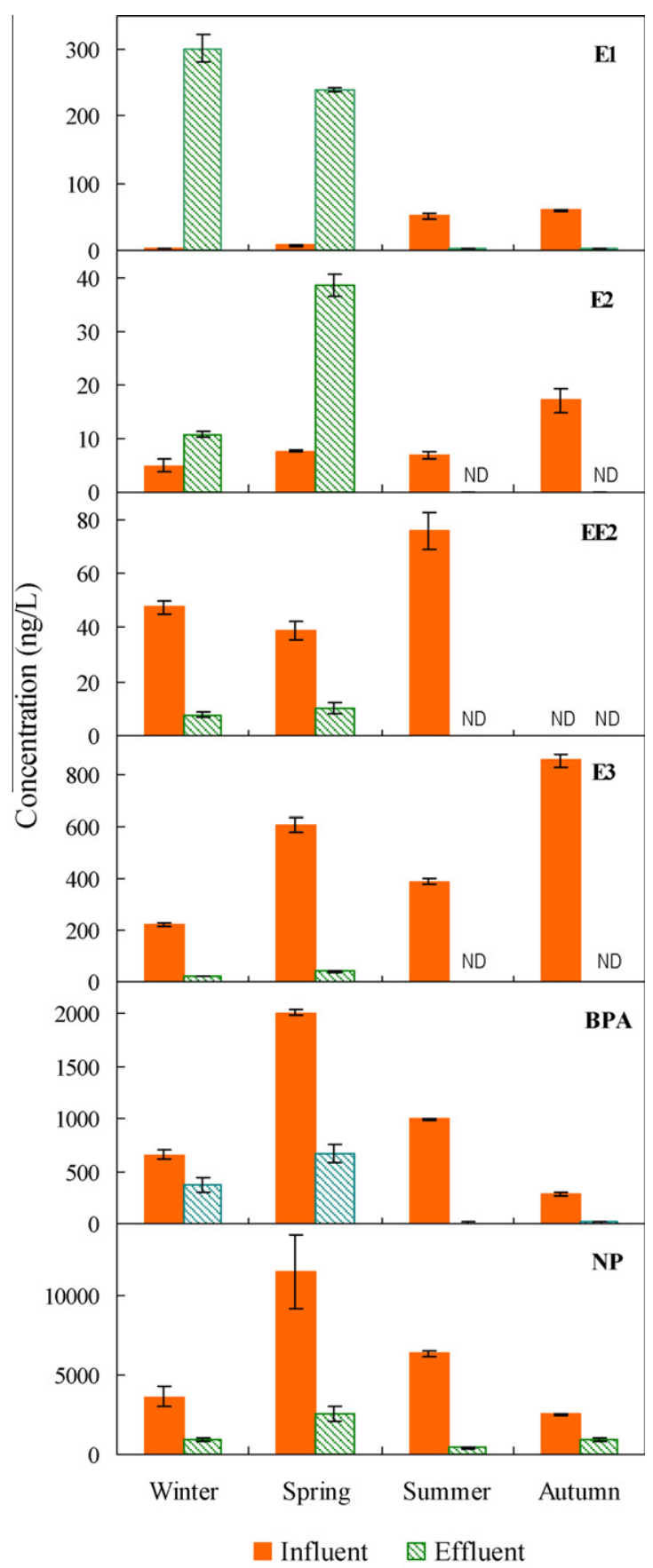

Fig. 3. Seasonal variation of the concentrations of studied EDCs in the influent and effluent of the $\mathrm{A} / \mathrm{A} / \mathrm{O}$ bioreactor.

ondary effluent and compared with the influent concentrations to assess the seasonal variation of EDCs removal in the bioreactor.

Fig. 3 shows that the effluent concentrations of E1 and E2 were much higher than their influent concentrations in winter and spring. For example, the effluent concentration of E1 in winter reached $301.5 \mathrm{ng} / \mathrm{L}$, which was almost 90 times its influent concentration $(3.5 \mathrm{ng} / \mathrm{L})$. However, in summer and autumn, the effluent concentrations of E1 and E2 decreased remarkably and E2 was even not detected. It clearly shows that the removal of E1 and E2 had a significant seasonal fluctuation in the STP. Much undegraded E1 and E2 would be discharged into the receiving water body in winter and spring, thus posing a threat to the affected aquatic ecosystems.
Koh et al. [31] found that every six-degree drop in sewage temperature could decrease the removal efficiency of E1 sulfate by ca. $20 \%$ in a nitrifying/denitrifying process, thus inferring that the low temperature in winter could bring down the activity of arylsulfatase enzymes or reduce the bacteria population containing these enzymes. In Northern China, the ambient temperature usually drops below $0{ }^{\circ} \mathrm{C}$ in winter, so the temperature of wastewater in municipal sewers is only about $10^{\circ} \mathrm{C}$. Under this condition, the conjugated E1 and E2 could not be effectively deconjugated during transport in sewers. Once entering the STP, the deconjugation of E1 and E2 would take place fast in the bioreactor that is rich in various enzymes, leading to a remarkable increase of the free-form concentrations in the effluent. Besides, a significant portion of E2 could be biodegraded to E1, thus the effluent concentration of E1 largely exceeded that of E2. Baronti et al. [8] also reported that the effluent concentration of E1 was higher than its influent concentration in some STPs in winter.

Both EE2 and E3 could be effectively removed by the A/A/O process. The influent concentration of EE2 fluctuated from 0 (autumn) to $75.7 \mathrm{ng} / \mathrm{L}$ (summer), and its removal efficiency varied from $74 \%$ to $100 \%$ with seasons. E3 had the highest influent concentration (221.5-855.8 ng/L) throughout one year among the studied estrogens, but its effluent concentration kept at a low level $(\leq 41.3 \mathrm{ng} /$ L) even in winter and spring. Wang and Ivanov [32] reported that E3 was only next to E2 in biodegradability among the studied estrogens.

The seasonal variations of BPA and NP concentrations in the influent and effluent exhibited a quite similar trend. The influent concentration of BPA fluctuated from 281.1 to $2004.5 \mathrm{ng} / \mathrm{L}$, and its removal efficiency varied from $44 \%$ in winter to $99 \%$ in summer. NP had the highest influent concentration of $2500-11,494 \mathrm{ng} / \mathrm{L}$ among the studied EDCs due to its extensive usage as surfactant. Its removal efficiency ranged from $63 \%$ to $93 \%$.

The removal of target EDCs showed significant seasonal dependence due to two facts: (1) the microorganisms became more active as the wastewater temperature increased and (2) the MLSS concentration continuously increased in the A/A/O bioreactor from winter to autumn (see Section 2.3). The removal efficiency of studied EDCs significantly relied on the MLSS concentration. For example, even the wastewater temperatures were close in spring $\left(19^{\circ} \mathrm{C}\right)$ and autumn $\left(18^{\circ} \mathrm{C}\right)$, a notably higher removal efficiency of studied EDCs was generally observed in autumn due to its higher MLSS concentration. Khanal et al. [33] thought that a high solids retention time (SRT) or MLSS concentration would benefit the removal of estrogens from wastewater. Consequently, a possible strategy for improving the removal of EDCs in cold seasons is to increase the MLSS concentration in the bioreactor by extending the SRT.

\subsubsection{Variation of EDCs concentrations in the solid phase of return sludge}

The concentrations of EDCs distributed in the solid phase of return sludge also exhibited an obvious seasonal fluctuation, as shown in Fig. 4. In general, their concentrations were much higher in winter and spring than in summer and autumn. E1 reached a maximal concentration $(138.1 \mathrm{ng} / \mathrm{g} \mathrm{SS})$ in winter, while E2, EE2 and E3 reached a maximal concentration of 22.0, 28.5 and $12.5 \mathrm{ng} / \mathrm{g}$ SS in spring, respectively. The concentrations of BPA and NP ranged from 18.9 to $91.0 \mathrm{ng} / \mathrm{g}$ SS and 3.6 to $19.9 \mu \mathrm{g} / \mathrm{g} \mathrm{SS}$, respectively, in four seasons. Aparicio et al. [34] reported that the concentrations of NP in the secondary sludge samples, which were collected from four STPs located in Seville of Spain, ranged from 12.4 to $143.7 \mu \mathrm{g} / \mathrm{g}$ SS in winter and spring. Stasinakis et al. [12] reported that the concentrations of BPA in the sludge collected from five STPs in Greece ranged from 560 to $1750 \mathrm{ng} / \mathrm{g}$ SS. These STPs only adopted a primary activated sludge process with a compara- 


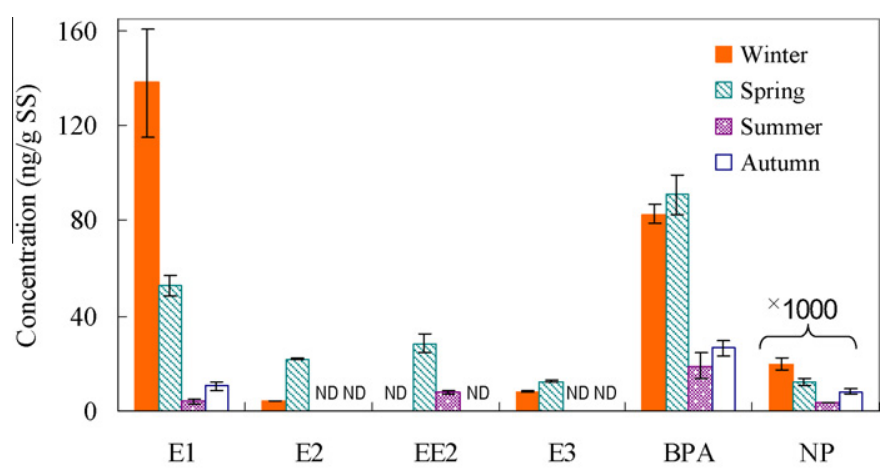

Fig. 4. Seasonal variation of the concentrations of studied EDCs in the solid phase of return sludge.

Table 3

The $\log K_{d}$ values of target EDCs in the return sludge $(\mathrm{L} / \mathrm{kg})$.

\begin{tabular}{lllllll}
\hline & E1 & E2 & EE2 & E3 & BPA & NP \\
\hline Winter $^{\mathrm{a}}$ & 2.66 & 2.60 & - & 2.59 & 2.36 & 4.33 \\
Spring $^{\mathrm{a}}$ & 2.34 & 2.76 & 3.45 & 2.48 & 2.13 & 3.68 \\
Average $^{\mathrm{a}}$ & 2.50 & 2.68 & 3.45 & 2.54 & 2.25 & 4.00 \\
Koh et al. [31] & 2.40 & 2.67 & 3.35 & 2.35 & - & 3.2 \\
$\log K_{\text {ow }}$ & $3.43^{\mathrm{b}}$ & $3.94^{\mathrm{b}}$ & $4.15^{\mathrm{b}}$ & $2.81^{\mathrm{b}}$ & $3.32^{\mathrm{c}}$ & $4.48^{\mathrm{c}}$ \\
\hline
\end{tabular}

a This study.

b Ref. [25].

c Ref. [28].

tively shorter SRT, which probably accounted for the less removal of EDCs than the A/A/O process examined in this study.

The apparent $K_{d}$ values of target EDCs in the secondary sedimentation tank were calculated in winter and spring when a relatively higher level of EDCs was detected in both liquid and solid phases of return sludge (Table 3 ). Results indicate that the average $\log K_{d}$ values of target EDCs (except E3) followed the same order as their $\log K_{o w}$ values, and were also similar to those reported by Koh et al. [31]. On this basis, the distribution proportion of each EDC in the solid phase of return sludge $(D)$ could be readily estimated by the following equation [33]:

$D(\%)=\frac{\text { MLSS } \times K_{d}}{1+\operatorname{MLSS} \times K_{d}} \times 100$

where the units of MLSS and $K_{d}$ are g/L and L/g, respectively. For example, the $D$ values of E1, E2, EE2, E3, BPA and NP in spring were calculated to be $59.6 \%, 79.2 \%, 94.9 \%, 70.0 \%, 47.7 \%$ and $97.0 \%$, respectively. It is seen that the activated sludge acts as a major sink for the majority of studied EDCs in the STPs. This result raises a particular concern about the disposal of excess sludge because of the presence of a significant amount of undegraded EDCs in cold seasons.

\section{Conclusions}

This work investigated, in a more comprehensive manner, the fate and seasonal variation of several typical EDCs in both wastewater and activated sludge of an A/A/O STP located in Beijing, China. Based on the obtained results, the following conclusions are drawn:

- In summer, the A/A/O STP could achieve an effective removal of all target EDCs. The removal efficiency of E1 reached $75.4 \%$, while those of other studied EDCs were all greater than $90 \%$. Biodegradation mostly accounted for the removal of EDCs.

- The removal efficiency of EDCs in the A/A/O bioreactor showed an obvious seasonal fluctuation, i.e., a higher removal was observed in summer and autumn than in winter and spring.
The variation of EDCs concentrations in the solid phase of return sludge exhibited a similar trend.

- It is noted that in winter and spring, the concentrations of E1 and E2 in the effluent largely exceeded those in the influent. Therefore, the conjugated forms of studied estrogens should also be analyzed in the future study to better understand the fate and behavior of EDCs in the STPs.

- The excess sludge contained a relatively high level of undegraded EDCs in cold seasons, thus its appropriate disposal should be concerned.

\section{Acknowledgments}

This study was financially supported by the National Natural Science Foundation of China (50921064, 20707032) and the Ministry of Science and Technology of China (2008ZX07101-006-08, 2009BAC57B02).

\section{References}

[1] J.E. Harries, D.A. Sheahan, S. Jobling, P. Matthiessen, P. Neall, J.P. Sumpter, T. Tylor, N. Zaman, Estrogenic activity in five United Kingdom rivers detected by vitellogenesis in caged male trout, Environ. Toxicol. Chem. 16 (1997) 534-542.

[2] L.J. Mills, C. Chichester, Review of evidence: are endocrine-disrupting chemicals in the aquatic environment impacting fish populations?, Sci Total Environ. 343 (2005) 1-34.

[3] O. Tsutsumi, Assessment of human contamination of estrogenic endocrinedisrupting chemicals and their risk for human reproduction, J. Steroid Biochem. 93 (2005) 325-330.

[4] J.W. Birkett, J.N. Lester, Endocrine Disrupters in Wastewater and Sludge Treatment Processes, IWA Publishing, London, 2003.

[5] C.E. Purdom, P.A. Hardiman, V.J. Bye, N.C. Eno, C.R. Tyler, J.P. Sumpter, Estrogenic effects of effluents from sewage treatment works, Chem. Ecol. 8 (1994) 275-285.

[6] B.L. Lei, S.B. Huang, Y.Q. Zhou, D.H. Wang, Z.J. Wang, Levels of six estrogens in water and sediment from three rivers in Tianjin area, China, Chemosphere 76 (2009) 36-42.

[7] J.L. Zhao, G.G. Ying, L. Wang, J.F. Yang, X.B. Yang, L.H. Yang, X. Li, Determination of phenolic endocrine disrupting chemicals and acidic pharmaceuticals in surface water of the Pearl Rivers in South China by gas chromatographynegative chemical ionization-mass spectrometry, Sci. Total Environ. 407 (2009) 962-974.

[8] C. Baronti, R. Curini, G. D’Ascenzo, A. Di Corcia, A. Gentili, R. Samperi, Monitoring natural and synthetic estrogens at activated sludge sewage treatment plants and in a receiving river water, Environ. Sci. Technol. 34 (2000) 5059-5066.

[9] T.A. Ternes, M. Stumpf, J. Mueller, K. Haberer, R.-D. Wilken, M. Servos, Behavior and occurrence of estrogens in municipal sewage treatment plants-I. Investigations in Germany, Canada and Brazil, Sci. Total Environ. 225 (1999) 81-90.

[10] H. Andersen, H. Siegrist, B. Halling-Sorensen, T.A. Ternes, Fate of estrogens in a municipal sewage treatment plant, Environ. Sci. Technol. 37 (2003) 40214026.

[11] N. Nakada, T. Tanishima, H. Shinohara, K. Kiri, H. Takada, Pharmaceutical chemicals and endocrine disrupters in municipal wastewater in Tokyo and their removal during activated sludge treatment, Water Res. 40 (2006) 3297 3303.

[12] A.S. Stasinakis, G. Gatidou, D. Mamais, N.S. Thomaidis, T.D. Lekkas, Occurrence and fate of endocrine disrupters in Greek sewage treatment plants, Water Res. 42 (2008) 1796-1804.

[13] Z.H. Liu, Y. Kanjo, S. Mizutani, Removal mechanisms for endocrine disrupting compounds (EDCs) in wastewater treatment-physical means, biodegradation, and chemical advanced oxidation: a review, Sci. Total Environ. 407 (2009) 731-748.

[14] S. Jin, F. Yang, T. Liao, Y. Hui, Y. Xu, Seasonal variations of estrogenic compounds and their estrogenicities in influent and effluent from a municipal sewage treatment plant in China, Environ. Toxicol. Chem. 27 (2008) 146-153.

[15] H.D. Zhou, X. Huang, X.L. Wang, X.H. Zhi, C.D. Yang, X.H. Wen, Q.H. Wang, H. Tsuno, H. Tanaka, Behaviour of selected endocrine-disrupting chemicals in three sewage treatment plants of Beijing, China, Environ. Monit. Assess. 161 (2010) 107-121.

[16] M. Auriol, Y. Filali-Meknassi, R.D. Tyagi, C.D. Adams, R.Y. Surampalli, Endocrine disrupting compounds removal from wastewater, a new challenge, Process Biochem. 41 (2006) 525-539.

[17] D Martinović, J.S. Denny, P.K. Schmieder, G.T. Ankley, P.W. Sorensen, Temporal variation in the estrogenicity of a sewage treatment plant effluent and its biological significance, Environ. Sci. Technol. 42 (2008) 3421-3427.

[18] Y. Nie, Z. Qiang, H. Zhang, C. Adams, Determination of endocrine-disrupting chemicals in the liquid and solid phases of activated sludge by solid phase 
extraction and gas chromatography-mass spectrometry, J. Chromatogr. A 1216 (2009) 7071-7080.

[19] APHA, Standard Methods for the Examination of Water and Wastewater, 21st ed., American Public Health Association, Washington D.C., 2005.

[20] G. D’Ascenzo, A. Di Corcia, A. Gentili, R. Mancini, R. Mastropasqua, M. Nazzari, R. Samperi, Fate of natural estrogen conjugates in municipal sewage transport and treatment facilities, Sci. Total Environ. 302 (2003) 199-209.

[21] H.B. Lee, D. Liu, Degradation of 17 beta-estradiol and its metabolites by sewage bacteria, Water Air Soil Pollut. 134 (2002) 353-368.

[22] F. Li, R. Desmiarti, A. Yuasa, A. Horio, Behavior of natural estrogens in semicontinuous activated sludge biodegradation reactors, Bioresour. Technol. 99 (2008) 2964-2971.

[23] T. Hashimoto, T. Murakami, Removal and degradation characteristics of natural and synthetic estrogens by activated sludge in batch experiments, Water Res. 43 (2009) 573-582.

[24] T. Urase, T. Kikuta, Separate estimation of adsorption and degradation of pharmaceutical substances and estrogens in the activated sludge process, Water Res. 39 (2005) 1289-1300.

[25] G.-G. Ying, R.S. Kookana, Y.-J. Ru, Occurrence and fate of hormone steroids in the environment, Environ. Int. 28 (2002) 545-551.

[26] A.C. Johnson, J. Sumpter, Removal of endocrine-disrupting chemicals in activated sludge treatment works, Environ. Sci. Technol. 35 (2001) 4697-4703.

[27] T.A. Ternes, P. Kreckel, J. Mueller, Behaviour and occurrence of estrogens in municipal sewage treatment plants-II. Aerobic batch experiments with activated sludge, Sci. Total Environ. 225 (1999) 91-99.
[28] G.-G. Ying, B. Williams, R. Kookana, Environmental fate of alkylphenols and alkylphenol ethoxylates-a review, Environ. Int. 28 (2002) 215-226.

[29] P. Pothitou, D. Voutsa, Endocrine disrupting compounds in municipal and industrial wastewater treatment plants in Northern Greece, Chemosphere 73 (2008) 1716-1723.

[30] H.R. Andersen, M. Hansen, J. Kjolholt, F. Stuer-Lauridsen, T.A. Ternes, B. Halling-Sorensen, Assessment of the importance of sorption for steroid estrogens removal during activated sludge treatment, Chemosphere 61 (2005) 139-146.

[31] Y.K.K. Koh, T.Y. Chiu, A.R. Boobis, M.D. Scrimshaw, J.P. Bagnall, A. Soares, S. Pollard, E. Cartmell, J.N. Lester, Influence of operating parameters on the biodegradation of steroid estrogens and nonylphenolic compounds during biological wastewater treatment processes, Environ. Sci. Technol. 43 (2009) 6646-6654.

[32] X.H. Wang, V. Ivanov, Microbial structure of nitrifying granules and their estrogens degradation properties, Water Sci. Technol. 59 (2009) 1855-1862.

[33] S.K. Khanal, B. Xie, M.L. Thompson, S.W. Sung, S.K. Ong, J. Van Leeuwen, Fate, transport, and biodegradation of natural estrogens in the environment and engineered systems, Environ. Sci. Technol. 40 (2006) 6537-6546.

[34] I. Aparicio, J.L. Santos, E. Alonso, Simultaneous sonication-assisted extraction, and determination by gas chromatography-mass spectrometry, of di-(2ethylhexyl)phthalate, nonylphenol, nonylphenol ethoxylates and polychlorinated biphenyls in sludge from wastewater treatment plants, Anal. Chim. Acta 584 (2007) 455-461. 